\title{
A Planet for Life: Building the Future We Want
}

\author{
Rajendra K Pachauri, Anne Paugam, Teresa Ribera, and Laurence Tubiana \\ (eds). 2015. New Delhi: The Energy and Resources Institute (TERI). \\ Reviewed by Nitish Arora, Research Associate, Centre for Global \\ Agreements, Leg. \& Trade, TERI
}

Sustainable development is perhaps the greatest challenge humanity has ever faced. The issue has galloped almost the entire world, not distinguishing between rich and poor countries, reeling under the pressure for sustaining life on planet earth. Building the Future We Want has come at a critical juncture as 2015 witnessed three landmark events: (i) Addis Ababa conference on developmental financing; (ii) adoption of sustainable developmental goals; and, (iii) Paris COP21. Before dwelling into the nitty-gritties of the book, I would briefly layout its background. It has been divided into three parts, first being negotiating a framework to be on a sustainable path. Second, it deals with what five continents have been doing to percolate green growth strategies into their developmental plans, in their exploration of pathway to sustainable development? Third, it is majorly concerned with financing and implementation issues. Since the challenge has never been so daunting it calls for innovative solutions.

Sustainable development has always been propagated as a mechanism which gives equal importance to the triad strand of economy, society, and the environment. However, often social and environmental aspects are underpinned with too much emphasis on economic policy, which is perhaps why the book presents a case for changing the way development is measured and the need to go beyond the GDP criteria. These 'beyond
GDP' measures encapsulate indicators for economy, environment, governance, and social development indicators. But the question that needs to be pondered upon is that given the ever increasing needs of mankind, even the proposed trajectory over time may become unsustainable. The tussle between social demographic forces and neo-liberal forces continues to act as an impediment in negotiating a sustainable future, which not only calls for integrating national developmental plans with global objectives; but also for galvanizing public opinion and encouraging development cooperation. The global climate negotiations have not been fruitful due to overriding political clout in the decision making of Global North over the developing countries of Global South, as the former continues to maintain a dominant share of the atmospheric 'carbon space', and thus, the fair-share concept seems far from getting realized. The book dwells with reinventing modes of participation in intergovernmental negotiations, for instance in Rio $20+$, Brazil has been innovative in inculcating the values of informed citizenry for setting up the public priorities although it has its own costs and complexities.

It then makes a systematic attempt to unravel how different territories are addressing the multifaceted issue of sustainable development. For instance, India in its pursuit of sustainable development should strive to keep up the pace of economic growth and also control for greenhouse 
gas emissions. Moreover, with accelerating growth and population, the demand for energy will be sky-rocketing, implying that the onus lies on increasing the share of renewable energy which can address the infrastructure bottlenecks as well. It was suggested that developing targeted business models can address the dual objective of building institutional capacity which promotes improvisation and deployment of requisite technologies, thereby lowering the effective cost of renewable energy and ensuring access at a reasonable price. As far as the Arab world is concerned, it is grappling with issues of population explosion, rural urban migration, wars, stagnating investment, and increasing unemployment which ignited the Arab Spring. This led the author asking how to combat jihadism? Through war or development? The upheavals of Arab Spring calls for changing the development model from a centralized one to cooperative one, where development can be brought by integrating the two sides of the Mediterranean; here Europe can play the role of merger in their mutual strive towards stability. Russia's growth trajectory, riding on export-led growth of raw materials does not seem to be sustainable, forcing it to shift to a model based on knowledge and technologies. Similar to India, it needs to unlock opportunities for capitalizing on its significant potential of renewable energy. Brazil had made substantial progress in reducing forest carbon emissions, however, its pathway to sustainable development is at the crossroads with too much emphasis on expanding agri business which encroaches upon forest cover. This might lead to social and environmental issues taking a backseat in country's development model.

California had been the pioneer in stipulating action for reducing GHG emissions and improved energy efficiency. International and regional cooperation (agreements with South America, India, China, Japan, Israel, and Mexico) has played a stupendous role in its stride towards low carbon development and investment in clean energy technologies. Moreover, California's case illustrates that expansion of renewable energy can be achieved without sacrificing on growth and employment. However, it has long way to go, as the 2050 emission target requires reduction at 2.5 times the current pace. Strikingly, Japan aims to be a anthropogenetic society by 2030 , where health, education, and culture are at the forefront. Although the aforementioned rationale is not in contrast with ecological sustainability, the problem arises on account of Japan's demographic component; a declining population with an aging one. The increasing social security expenditure raises questions about the viability of the model. On other hand, the South Korean model thrives on Green Growth Strategies in their pursuit for sustainable development. However, it has come under some serious pressure, as nuclear energy, one of its major pillars has suffered a setback after the Fukushima turmoil.

The other most discernible issue of this book is that it gives credence to the idea of reinventing development and its financing. Until now, official development assistance has been a fragile source of funding for developing countries, creating a stable financial system which is pivotal to achieve post the 2015 developmental agenda. The Addis Ababa conference aims at reviving official development assistance, which forms a crucial component for financing development in LDCs. Further it needs to be understood that the choice of financial instrument is country- and sector-specific, for instance, blended finance could be one of the vehicles driving sustainable development in LDCs, asserting the need to go beyond official development assistance. Although, over time with China's rise, the discourse of economic, political, and power relations have tweaked upside down. It has resulted in the formation of new development financing institutions (New Development Bank, BRICS, Asian Infrastructure Investment Bank, Silk Road Fund) by middle income countries constituting a major step forward, overcoming the deadlock of finance. This means that mobilizing domestic funds becomes critical to finance sustainable development. Coming to COP21, the major task ahead would be to break the vicious circle of distrust that has built up around the climate issue. 
In the hindsight of past discourse, it lastly pitches the issue of 'reinventing civilization' which can be resilient to crisis. This requires new hierarchy of values and institutions that are participatory, decentralized, and equitable. The mindset needs to change from status-oriented to change-oriented which can set a pathway to better society. Other issues highlighted include social justice, health policy, and importance of disaster risk reduction, an understanding of which is pivotal as we move towards sustainable development.

The book uncovers new perspectives and ideas from multiple disciplines around the world: economics, politics, natural and human sciences, and cultural studies, providing a factual background and envisioning solutions for the great challenges of humanity. Moreover, the book has extensively used charts, tables, maps, and thematic focus essays which get imprinted on the reader's mind; it makes a systematic attempt to corroborate theory with facts and figures which make the claims of the book more substantive. Far more than a rhetorical exercise, this book is designed to inform, inspire, and spur action. It enlightens a new ray of hope and perhaps, a clarion call for all who care about our planet and social justice. This is an essential book for anyone who wants to understand the present and future challenges for humanity. We live in an extremely critical moment, whatever happens in the next 20 years, whatever we as a species decide to do, will probably decide our survival.

Life on the planet is at the cusp of a major change which requires a more pragmatic approach that will steer the ship in the direction of meeting the sustainable development goals, otherwise at the crack of dawn, it will all be doomed. Changing the pattern of incentives and disincentives that govern consumption and the lifestyle behaviour of citizens, fostering international cooperation, and focussing on actions rather than negotiations can help us building the future we want! 